\section{Surface topography of Dome A, Antarctica, from differential GPS measurements}

Dome $A$ is the highest ice feature in Antarctica, at over 4000 m a.s.I., and overlies the Gamburtsev mountains. It is believed that deep ice-core drilling in this area may reveal the oldest ice in Antarctica, providing an unparalleled paleoclimate record in excess of $1 \mathrm{Ma}$, and perhaps going back as far as 1.2 Ma (Xiao and others, 2008). However, little is known about this area because its height and distance from the coast and scientific stations makes access difficult.

Surface elevation information for the Dome A area is available only from the RADARSAT-1 Antarctic Mapping Project (RAMP) digital elevation model (DEM) compiled from altimeter data (Liu and others, 1999) and from data covering a small area of $\sim 64 \mathrm{~km}^{2}$ centered on the observed summit point $\left(80^{\circ} 22^{\prime} 01.6^{\prime \prime} \mathrm{S}, 77^{\circ} 22^{\prime} 22.9^{\prime \prime} \mathrm{E}, 4092.75 \mathrm{~m}\right.$ a.s.l.) (Zhang and others, 2007). This small area was surveyed using realtime kinematic (RTK) GPS in early 2005, and 480 global positioning system (GPS) points were used to build the topography. The results show that the lowest surface height within the grid is $4090.20 \mathrm{~m}$, giving an elevation range of $2.7 \mathrm{~m}$ (surface slope $<0.08 \%$ ) over the entire $64 \mathrm{~km}^{2}$. Groundbased ice-penetrating radar (GPR) measurements were also made at that time. The main purpose of the fieldwork was to aid future selection of the best site for deep ice-core drilling in the region. However, the survey and GPR results indicated that a larger area needed to be studied before the site selection could be finalized. For the 2007/08 Dome A traverse, therefore, the primary task was to increase the survey area.

We present measurements of surface topography of the summit area of Dome $A$, based on post-processing of differential GPS data. Fast-static differential GPS is a useful tool in measuring surface topography in the Antarctic interior, because it allows high-precision measurements to be made relatively quickly with minimal logistical support. The post-processing fast-static differential technique was chosen, as the distance maximum $(14 \mathrm{~km})$ between the rover and the base station exceeds the communication limit of the radio of the GPS system.

\section{METHODS}

Three Leica 1230 dual-frequency GPS receivers were used for the kinematic survey. A reference GPS station was established at the base camp of the Chinese Dome A expedition team, $\sim 7 \mathrm{~km}$ southwest of the Dome A summit. The GPS antenna was mounted on a tripod $\sim 6 \mathrm{~m}$ from a sled cabin, and the GPS receiver was placed in the cabin and powered by a generator. A transmitting radio was connected to the GPS receiver with the antenna mounted on the roof of the cabin through a blowhole (Fig. 1a). This reference GPS receiver conducted continuous observation from 13 to 26 January 2008, with an observation interval of $5 \mathrm{~s}$.

The other two GPS receivers (one for back-up, operated in RTK mode) were used as roving stations, installed on a Pisten Bully 300 over-snow vehicle (Fig. 1b). The survey was carried out on a mixed grid of rectangles and diagonals covering a $20 \times 20 \mathrm{~km}$ square, centered on the camp. Within the grid, static GPS measurements were taken at each $5 \times 5 \mathrm{~km}$ gridpoint (circle with crosses in Fig. 2) for at least $20 \mathrm{~min}$, which serve as checkpoints for later mapping. RTK observations by the back-up receiver served to check the quality of the fast-static method while the range was near enough to communicate with the base station.

The velocity of the over-snow vehicle ranged from 10 to $13 \mathrm{~km} \mathrm{~h}^{-1}$. The roving receiver was operated in static mode and the observation interval was set to $5 \mathrm{~s}$ with the sample distance at $\sim 15 \mathrm{~m}$. The sampling rate of RTK observation was $15 \mathrm{~s}$. The field survey started on 18 January and ended on 22 January. A total of nearly 20000 static point measurements were made. The RTK observations turned out to be of high accuracy only to within $5 \mathrm{~km}$ of the base station.

The GPS data from the reference station during the period 17-23 January were processed using the GAMIT/GLOBK software (King, 2002), developed at Massachusetts Institute of Technology. Six International GNSS Service (IGS) stations around Antarctica, DAV1 (Davis Station), DUM1 (Dumont d'Urville Station), MCM4 (NASA McMurdo Ground Station), OHG2 (O'Higgins Station), SYOG (Syowa Station) and VESL (SANAE IV Station), were involved in the processing.
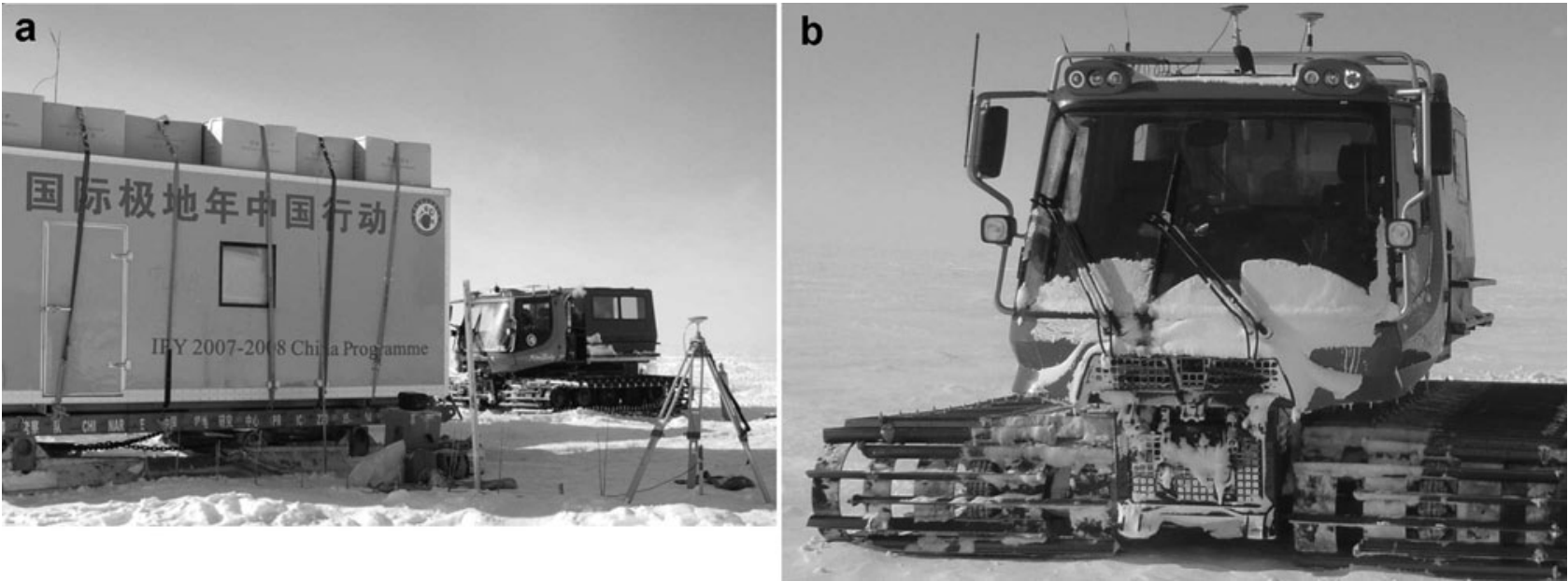

Fig. 1. (a) The reference GPS station at the base camp. The green cabin is the living quarters, the GPS antenna is installed on a tripod and the radio antenna is on the top of the cabin. (b) The dual roving GPS receivers mounted on the Pisten Bully 300 over-snow vehicle. The two antennas are on top of the vehicle and the radio antenna is on the top-left side of the cab. 


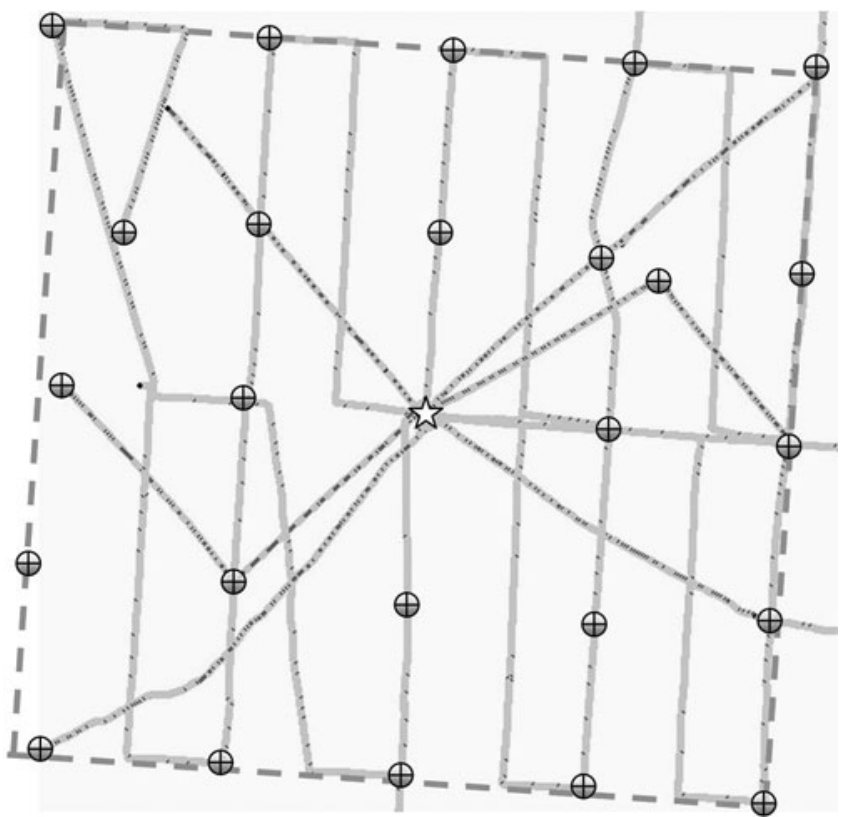

Fig. 2. The track lines of the roving GPS survey in the Dome A region. The rectangular region of interest, indicated using a dashed line, is the predefined area $(20 \times 20 \mathrm{~km})$ of the survey. The base camp of the expedition team is at the center of the area. The circles with crosses denote the location of static GPS checkpoint measurements, taken over periods of at least $20 \mathrm{~min}$.

During the data processing, the following options were selected:

1. IGS SP3 precise ephemerides were used and held fixed. In GLOBK processing, the six IGS stations were tightly constrained (within $1 \mathrm{~cm}$ ) to their ITRF2000 values, while the site at Dome A was loosely constrained.
2. An elevation cut-off angle of $15^{\circ}$ was used; corrections were applied to model variations of the antenna phase center. The ionospheric-free linear combination of the L1 and L2 frequencies was used.

3. Corrections were applied for both the solid-Earth and frequency-dependent tides. The dry component of the zenith tropospheric delay was implemented using the Saastamoinen model. The wet component was estimated during the inversion, with zenith-delay adjustments every 2 hours. The calculated World Geodetic System 1984 (WGS84) coordinates of the reference station are $80^{\circ} 25^{\prime} 02.24023^{\prime \prime} \mathrm{S}, 77^{\circ} 06^{\prime} 32.26738^{\prime \prime} \mathrm{E}, 4091.235 \mathrm{~m}$ elevation. The estimated uncertainties for this station in the $x, y$ and $z$ directions are given by GLOBK as 0.0011 , 0.0011 and $0.0039 \mathrm{~m}$, respectively. No motion was detected for the reference station during the survey period. Based on the reference station, all the roving static observation data were processed using continuous faststatic strategy with Trimble GPSurvey software v2.35. The static observations over the 25 grid vertices were also processed.

In the GPSurvey, points with GPS uncertainties $>0.10 \mathrm{~m}$ in the vertical were eliminated. Taking into account the tracked vehicle penetration $(<0.10 \mathrm{~m})$ into the soft snow, our topography uncertainty is estimated to be $0.20 \mathrm{~m}$. Crosspoints of different track lines and the 25 checkpoints were used to check for inconsistencies; points deviating $\geq 0.2 \mathrm{~m}$ from the average were eliminated. Ultimately, 16480 points were used to build a topographic map. RTK observations were reprocessed according to the new accurate base stations.

Surfer V8.0 software was used to generate a contour map from distributed line values. The 'kriging' gridding technique was chosen for interpolation. The 25 checkpoints were used to adjust the interpolation setting to obtain the best-fit surface.

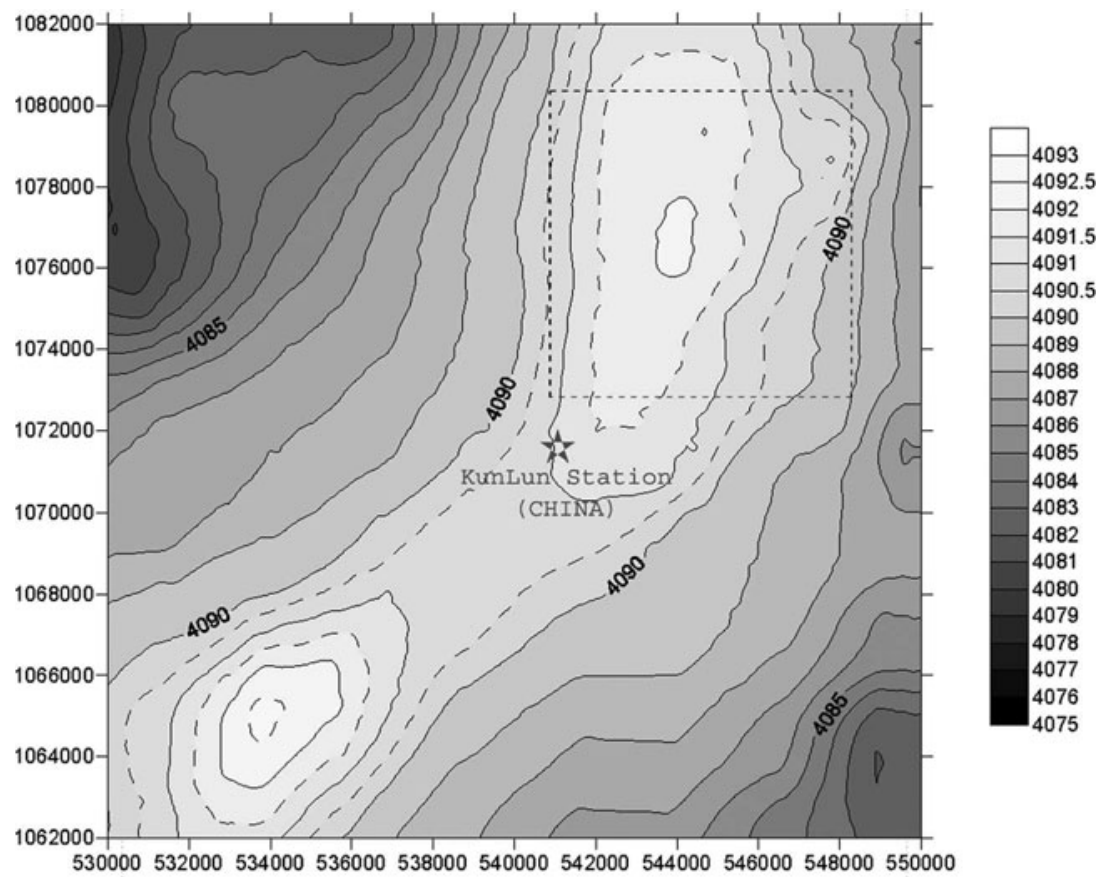

Fig. 3. Map of surface topography over the Dome A region surveyed by the 24th Chinese Antarctic National Research Expedition (CHINARE) in January 2008. Heights are with respect to the WGS84 system. The map is projected into the Universal Transverse Mercator (UTM) 43S zone. Contour interval is $1 \mathrm{~m}$ (with dashed contours at $0.5 \mathrm{~m}$ ). The dashed rectangle covering the northern peak is the $64 \mathrm{~km}^{2}$ area surveyed in early 2005 (Zhang and others, 2007). 


\section{RESULTS AND DISCUSSION}

Smoothed elevation contours were plotted at $1 \mathrm{~m}$ intervals (Fig. 3). To improve the topographic feature description, $0.5 \mathrm{~m}$ contour intervals (dashed curves) are shown for the elevation range $4090-4093 \mathrm{~m}$. The topography of the Dome $A$ region is saddle-shaped and very flat. The overall topographic height difference within the $400 \mathrm{~km}^{2}$ area is $<15 \mathrm{~m}$, and most of the area is above $4085 \mathrm{~m}$. There exist two peaks in this area. During the 2004/05 austral summer season, the northern peak was determined to be higher than the southern peak using just a single total-station instrument (Zhang and others, 2007). However, we found the southern peak to be $\sim 0.3 \mathrm{~m}$ higher than the northern peak. This height discrepancy may have resulted from accumulation or wind-transported snow during the intervening 3 years. It should be noted that the current kinematic survey technique is certainly more reliable than the single total-station technique used for the earlier spot measurements.

The location of the $64 \mathrm{~km}^{2}$ map of Dome A surveyed in early 2005 (Zhang and others, 2007) is indicated by a dashed rectangle in Figure 3. The stated uncertainty of Zhang and others' DEM is $\sim 0.20 \mathrm{~m}$, the same as ours. The overall topographic pattern is similar in the two maps. The new map covering a larger area, together with subglacial measurements, has been used to determine a site for the new ice-drilling station (Kunlun station; Fig. 3).

\section{ACKNOWLEDGEMENTS}

We thank the field team of 24th CHINARE and especially Wu Xuefeng of the Heilongjiang Bureau of Surveying and Mapping for his help. This work was supported by China's International Polar Year (IPY) PANDA (Prydz Bay-Amery Ice Shelf-Zhongshan-Dome A) program (Chinese Arctic and Antarctic Administration), the Chinese National Science Foundation (grant No. 40506001) and the National Scientific and Technological Support Program (grant No. 2006BAB18B01).
State Key Laboratory of Remote

Sensing Science,

Institute of Remote Sensing Applications,

Chinese Academy of Sciences,

Beijing 100101, China

Institute of Earthquake Prediction,

China Earthquake Administration,

Beijing 100036, China

National Geomatics Center of China

Zhanyi SUN

State Bureau of Surveying and Mapping,

No. 1. Baishengcun, Zizhuyuan,

Beijing 100044, China

Polar Research Institute of China,

State Ocean Administration,

Shanghai 200136, China

*Present address

College of Global Change and Earth System,

Beijing Normal University,

Beijing 100875, China

E-mail: xcheng@bnu.edu.cn

1 January 2009

\section{REFERENCES}

King, R.W. 2002. Documentation for the GAMIT GPS analysis software (Version 10.05). Cambridge, MA, Massachusetts Institute of Technology.

Liu, H., K.C. Jezek and B. Li. 1999. Development of an Antarctic digital elevation model by integrating cartographic and remotely sensed data: a geographic information system based approach. J. Geophys. Res., 104(B10), 23,199-23,213.

Xiao, C., Y. Li, S. Hou, I. Allison, B. Lingen and J. Ren. 2008. Preliminary evidence indicating Dome A (Antarctica) satisfying preconditions for drilling the oldest ice core. Chinese Sci. Bull., 53(1), 102-106.

Zhang, S., D. E, Z. Wang, C. Zhou and Q. Shen. 2007. Surface topography around the summit of Dome A, Antarctica, from real-time kinematic GPS. J. Glaciol., 53(180), 159-160. 